\title{
Geophysical Model Function for the AMSR2 C-Band Wind Excess Emissivity at High Winds
}

\author{
Zabolotskikh Elizaveta V. ${ }^{1}$, Reul Nicolas ${ }^{2}$, Chapron Bertrand ${ }^{2}$ \\ ${ }^{1}$ Russian State Hydrometeorol Univ, Satellite Oceanog Lab, St Petersburg 195196, Russia. \\ 2 Inst Francais Rech \& Exploitat Mer, F-29280 Plouzane, France. \\ Corresponding authors : email addresses : liza@rshu.ru ; $\underline{\text { nreul@ifremer.fr ; bchapron@ifremer.fr }}$
}

\begin{abstract}
:
Measurements of the Advanced Microwave Scanning Radiometer 2 (AMSR2) onboard GCOM-W1 satellite at 6.925 and $7.3 \mathrm{GHz}$ and both linear polarizations over tropical cyclones (TCs) during 2012 2014 are used to derive a new geophysical function relating the brightness temperature to the sea surface wind speed (SWS) in extreme conditions. . Similar sensitivity to SWS at close C-band frequencies allowed to correct for the atmospheric contributions to the microwave radiance and estimate the brightness temperature (TB) at the surface under the TCs, combining theoretical modeling and measured TB analyses. Estimated oceanic TBs were regressed against the wind speeds from the Best Track Archive to derive the new geophysical model function (GMF) for the wind speed excess emissivity at AMSR2 C-band microwave frequencies.
\end{abstract}

Keywords: Atmosphere, geophysical measurements, oceans, passive microwave remote sensing, tropical cyclones (TCs) 


\section{INTRODUCTION}

Remotely sensed measurements from passive and active microwave instruments ensure global wind mapping capabilities. Active microwave co-polarized backscatter signals of currently operating instruments saturate under hurricane force winds [1] and are heavily affected in presence of high rain rates, ensuring an increasing role of microwave radiometry. As it has already long been established [2]-[4], whitecaps, streaks and various associated foam structures at the ocean surface significantly contribute to increase the microwave emissivity of the sea surface. This emissivity increase is observable even when a very small portion of the sea surface is covered by foam formations. Contrarily to scatterometer signal, the radiometric signal does not saturate at high winds providing the potential for foam property and surface wind speed retrievals using passive microwave observations [2], [5]-[7]. Moreover, the sensitivity of microwave brightness temperature tends even to increase for the winds above $15 \mathrm{~m} / \mathrm{s}$ [8]-[10]. Nevertheless numerical estimations of the wind speed sensitivity at frequencies higher than L-band is essentially complicated by the intervening atmosphere. At $\mathrm{C}$ - and higher frequency bands, atmospheric absorption, emission and scattering associated with high cloud liquid and ice water content and intense precipitations in tropical cyclones (TCs) have large impacts on the brightness temperatures. Intensive rains both shield the ocean surface and change the ocean surface emissivity in a complicated manner. This influence is hard to be theoretically modeled especially for such extreme events combining very high precipitation rate and hurricane-force winds. Whereas the microwave radiation at L-band is almost transparent to atmosphere with negligible impacts of precipitation and water clouds with respect to those reported at higher frequency bands, L-band ocean emissivity is less sensitive to sea surface state changes at high winds than at the higher $\mathrm{C}$ - and $\mathrm{X}$-band microwave frequencies.

The new Japan passive microwave instrument Advanced Microwave Scanning Radiometer 2 (AMSR2), launched in May of 2012, has four C-band channels at the frequencies of 6.925 and $7.3 \mathrm{GHz}$. The two new C-band channel measurements, along with the other $\mathrm{C}$ - and $\mathrm{X}$-band measurements may be explored to estimate the rain radiance and atmospheric transmittance at C-band, since the signal at close frequencies has similar sensitivity to the sea surface wind speed but differs in the sensitivity to rain. Such estimation can help in the separation of the ocean signal from the total brightness temperature and derivation of the geophysical model function (GMF) that relates the surface excess emissivity and wind speed at the AMSR2 C-band microwave frequencies. In this study this GMF is derived through analyses of AMSR2 brightness temperature $\left(T_{B}\right)$ fields over an ensemble of TCs and the use of a radiative transfer forward model of the $T_{B}$.

\section{METHODOLOGY}

Simulation of the microwave brightness temperatures over the oceans as functions of frequency [1]-[3] shows that at Cband frequencies the radiative transfer equation (RTE) of emission type is valid for the rainfall range up to $20 \mathrm{~mm} / \mathrm{h}$. In the simplified form, the RTE for the brightness temperature of the atmosphere - ocean system $T_{B}$ can be written as:

$$
\cos \theta \cdot \frac{d T_{B}}{d z}=-\alpha(z) T_{B}+\alpha(z) T(z)
$$


This "absorption only" form of RTE, where the absorption coefficient $\alpha_{a b s o r p t i o n}$ is replaced by the total attenuation coefficient $\alpha$, accounts accurately for the negative effect of scattering and approximately for its positive effect due to the forward scattering [4]. Note that it does not account for the polarization effect of scattering which increases with rain rate.

The solution of the equation (1) can be written as:

$$
T_{B}=T_{a}+T_{a} \cdot(1-\varepsilon) \cdot \exp (-\tau)+T_{S} \cdot \varepsilon \cdot \exp (-\tau)
$$

Where $T_{a}$ is the radiation of the atmosphere, which in (2) is supposed to be equal in its upwelling and downwelling parts [5]; $\varepsilon$ is the sea surface emissivity, strongly dependant on the sea surface wind speed, $\tau$ is the atmospheric optical thickness and $T_{S}$ is the sea surface temperature (SST). The cosmic radiation is neglected in (2).

Expressing $T_{a}$ as $T_{\text {eff }} \tau$, where $T_{\text {eff }}$ is the effective atmospheric temperature we can further simplify (2) as:

$$
T_{B}=T_{\text {eff }} \cdot \tau+T_{\text {eff }} \cdot(1-\varepsilon) \cdot(1-\tau)+T_{S} \cdot \varepsilon \cdot(1-\tau)
$$

The sea surface emissivity $\varepsilon$ can be calculated through the following expression:

$$
\varepsilon=\frac{T_{B}-T_{e f f} \cdot \tau \cdot(2-\tau)}{T_{S}-T_{e f f} \cdot \tau}
$$

Thus, knowing $T_{B}, T_{S}, \tau$ and $T_{e f f}$, we can calculate $\varepsilon$ and relate it to the sea surface wind speed (SWS) to derive the geophysical model function (GMF) for wind speed dependency.

To parameterize $T_{\text {eff }}$, we used numerical calculations of the atmospheric contribution to the brightness temperature. An input data set of about 7000 radiosounding profiles from the tropical radiosounding stations, complemented by the model profiles of liquid water content and rain rate was used. The clear sky atmospheric radiation was evaluated using widely used and intensively validated models - [6] for molecular oxygen and [7] for water vapor absorption. Liquid water content absorption and rain rate attenuation were calculated using parameterization of [6]. Fig. 1 shows the dependency of $T_{a}$ on $\tau_{6.9}$ at $6.9 \mathrm{GHz}$ for the whole data set of the atmospheric parameter profiles. With some degree of accuracy we can define $T_{\text {eff }}$ as a constant of $260 \mathrm{~K}$ in (4). Numerical calculations also allow to express the atmospheric attenuation at $6.9 \mathrm{GHz}$ as $0.87 \cdot \tau_{10.65}$. The atmospheric attenuation at $10.65 \mathrm{GHz}$ can be presented as a sum of the atmospheric absorption $\tau_{0}$ of the system without rain, which can be estimated using the approach described in [8], and the attenuation of rain $\tau_{R}$ :

$$
\tau_{R}=0.0038 \cdot T_{R} .
$$

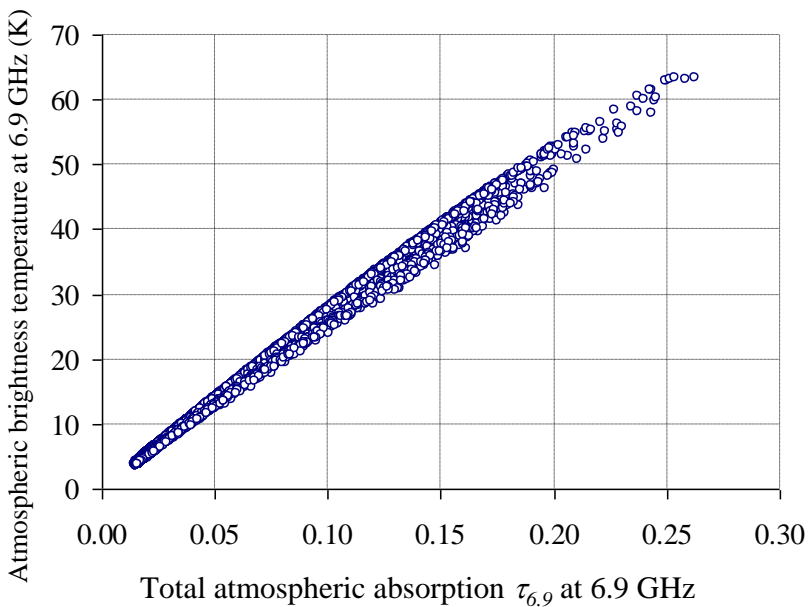

Fig. 1. Atmospheric brightness temperature $T_{a}$ at $6.9 \mathrm{GHz}$ as a function of the total atmospheric absorption $\cdot \tau_{6.9}$.

The equation (5) is the regression result of the numerical simulations, where $T_{R}$ presents the rain brightness temperature. In turn, $T_{R}$ can be separated from the brightness temperature of the atmosphere - ocean system encountered over a TC, using the method developed in [9]. Thus, reformulating (4) in terms of the brightness temperature functions we can write:

$$
\varepsilon_{6.9}=\frac{T_{B 6.9}-260 \cdot 0.87 \cdot \tau_{10.65} \cdot\left(2-0.87 \cdot \tau_{10.65}\right)}{T_{S}-260 \cdot 0.87 \cdot \tau_{10.65}}
$$

where

$$
\tau_{10.65}=\tau_{0}+0.0038 \cdot T_{R} \cdot
$$

Using AMSR2 measurements as input and applying formulas (7) and (6), we calculated the ocean emissivity $\varepsilon$ at $6.9 \mathrm{GHz}$ at both horizontal and vertical polarization. $\tau_{0}$ was calculated using the measurements at $10.65,18.7$ and 23.8 $\mathrm{GHz}$ at both horizontal and vertical polarizations and the Neural Network (NN) algorithm described in [8] was applied. $T_{R}$ was calculated using the differences in measurements between $\mathrm{C}$ - and X-band channels at vertical polarization as described in [9]. An independent satellite product described hereafter was used as a source for the sea surface temperature data.

\section{DATA}

The Tropical Cyclone information (Best Track Data) for 2012 - 2014 (years of AMSR2 available data) was downloaded from the National Hurricane Center (NHC) for the North Atlantic and Northeast Pacific TCs and from the Japan Meteorological Agency (JMA) (Regional Specialized Meteorological Center (RSMC) Tokyo - Typhoon Center) for the Northwest TCs.

AMSR2 Level 1B swath brightness temperature data were downloaded from the GCOM-W1 Data Providing service, Japan Aerospace Exploration Agency. AMSR2 Level 1B $T_{B}$ 
data at $\mathrm{C}$ - and $\mathrm{X}$-band channels are provided on the same irregular grid of $10 \mathrm{~km} \times 10 \mathrm{~km}$ [10], which simplifies the use of the data at different channels in the equations for the ocean emission calculations.

We used the $9 \mathrm{~km}$ microwave plus infrared (MW_IR) Optimally Interpolated (OI) SST product downloaded from the Remote Sensing Systems web site to characterize the fields of sea surface temperature $T_{S}$. ().

For the numerical calculations which allowed to parameterize $T_{a}=260 \cdot \tau_{6.9}, \tau_{6.9}=0.87 \cdot \tau_{10.65}$ and $\tau_{\mathrm{R}}=0.0038 \cdot T_{R}$ we used the data set of about 7000 radiosounding profiles of air temperature, humidity and pressure from the tropical weather stations, collected by the University of Wyoming. This data set consists in cloud liquid water content profiles, modeled in accordance with [11]. For those data which exhibited modeled total liquid water content less than $0.3 \mathrm{~kg} / \mathrm{m}^{2}$, we assumed an absence of rain drops. For cloudy conditions, characterized bytotal liquid water content exceeding $0.3 \mathrm{~kg} / \mathrm{m}^{2}$, uniformly distributing point rain rates were added randomly with rain rate (RR) from 0 up to 20 $\mathrm{mm} / \mathrm{h}$ within the rain depth of $0.5-4.5 \mathrm{~km}$, function ofthe humidity and temperature profiles.

\section{RESULTS}

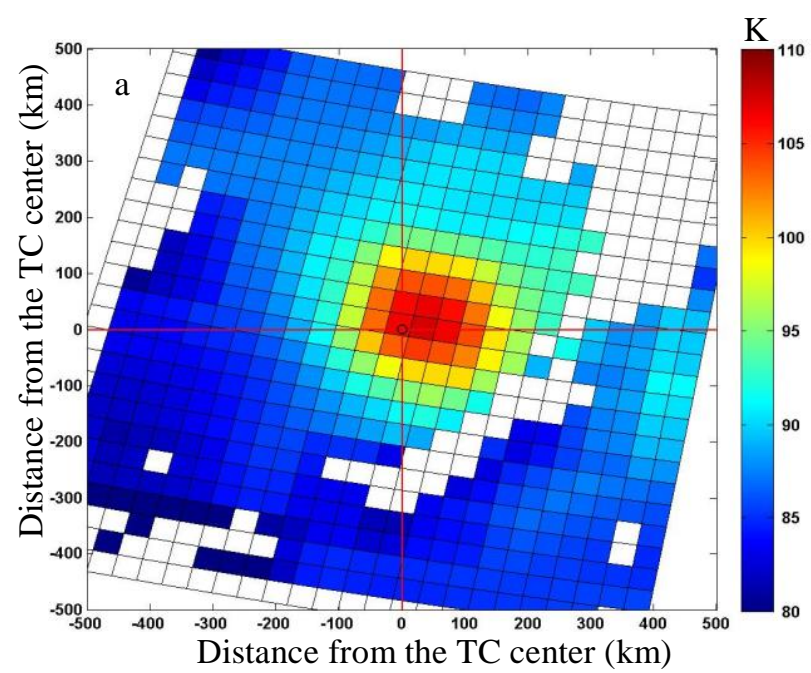

Using AMSR2 measurements, SST OI MW_IR product and the equations provided above, we estimated the ocean emissivity $\varepsilon$ at $6.9 \mathrm{GHz}$ at both horizontal and vertical polarization The fields of the ocean emissivity $\varepsilon$ at $6.9 \mathrm{GHz}$ at both horizontal and vertical polarization were built for 110 North Atlantic and North Pacific TCs intercepted by AMSR2 swath over the period 2012-2014. About 600 full intercepts were analyzed to match the maximum values of $\varepsilon$ over the TCs with the maximum 1-minute sustained surface wind speed estimates from the Best Track Archives, downscaled to 10-minute winds to correspond to the AMSR2 spatial resolution. Obtained provided The new GMF at both vertical and horizontal polarization for the microwave $\mathrm{C}$-band emission at high winds in Tropical Cyclones.was then obtained by relating $\varepsilon_{\max }$ at $6.9 \mathrm{GHz}$ and the maximum sustained wind $\mathrm{SWS}_{\max }$

An example of the fields of the calculated ocean radiances at $6.9 \mathrm{GHz}$, horizontal polarization $\Delta T_{\text {Bocean }}{ }^{H}=\varepsilon^{H} \cdot T_{S}$ and at $6.9 \mathrm{GHz}$, vertical polarization $\Delta T_{\text {Bocean }}{ }^{V}=\varepsilon^{V} \cdot T_{S}$ over the Typhoon Danas in the West Pacific Ocean on 7 October 2013 at 17:00 UTC are presented in Fig. 2. The coordinate system is linked to the center of the cyclone, the vertical axis corresponds to the storm translation movement direction, and the distances are given in $\mathrm{km}$ from the center of the cyclone. The masked (white) pixels in the Fig. 2 indicate land and coastal zones

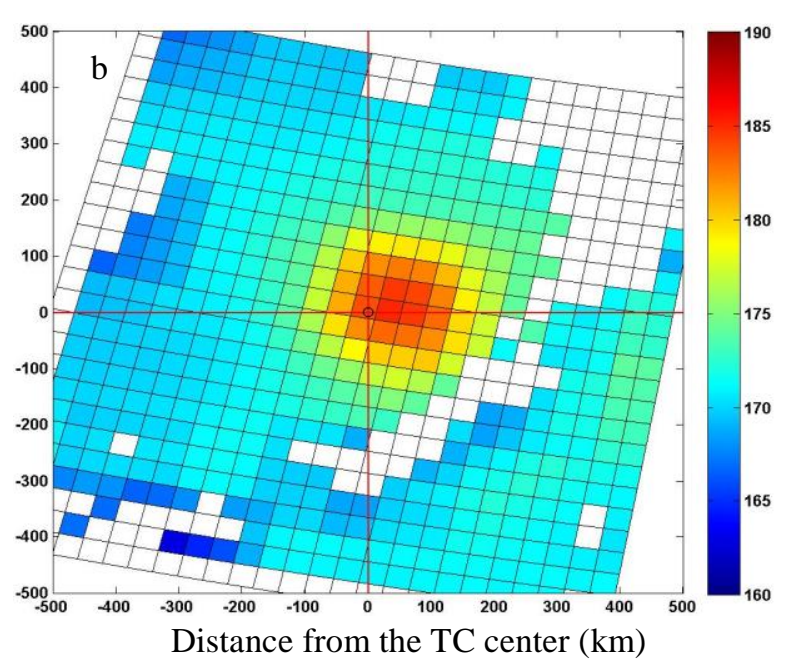

Fig. 2. The fields of the calculated ocean radiances at (a) $6.9 \mathrm{GHz}$, horizontal polarization $\Delta T_{\text {Bocean }}{ }^{H}$, and (b) at $6.9 \mathrm{GHz}$, vertical polarization $\Delta T_{\text {Bocean }}{ }^{V}$ over the Tropical Cyclone Danas in the West Pacific Ocean on 7 October 2013 at 17:00 UTC.

For that particular example, the maximum values of the wind-induced excess brightness temperature were of $\Delta T_{\text {Bocean }}{ }^{H}=108$ Kand $\Delta T_{\text {Bocean }}{ }^{V}=185 \mathrm{~K}$ in $\mathrm{H}$ and $\mathrm{V}$ polarization, respectively. The surface temperature was $T_{S}=$ $295 \mathrm{~K}$ and the maximum value of 1 -minute wind speed, taken from the Best Track Data archive of JMA (http://agora.ex.nii.ac.jp/digital-typhoon), is reported to be 40 $\mathrm{m} / \mathrm{s}$ at 18:00 UTC which corresponds to $37.2 \mathrm{~m} / \mathrm{s}$ of $10-$ minute wind. Therefore, for $\varepsilon^{H}$ at $37.2 \mathrm{~m} / \mathrm{s}$ we have the value of $108 / 295=0.37$, for $\varepsilon^{V}$ at $37.2 \mathrm{~m} / \mathrm{s}$ we have the value of $185 / 295=0.63$.

The derived ocean emissivities at $6.9 \mathrm{GHz}$ at horizontal and vertical polarizations following such methodology for about 600 AMSR2 intercepts of North Atlantic and North 
Pacific Tropical Cyclones were collected and are plotted as function of the 10-min SWS in Fig.3.

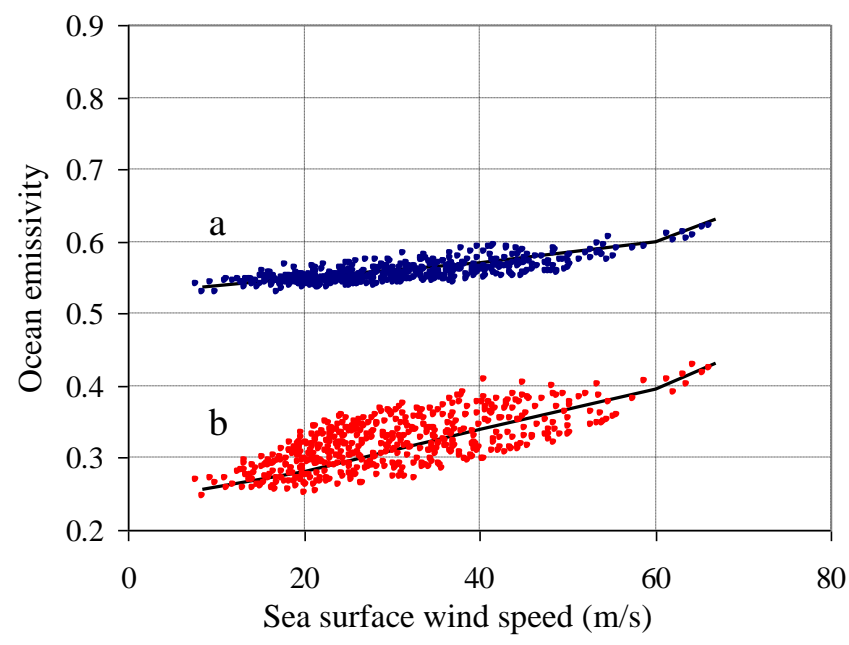

Fig. 3. Maximum values of the ocean emissivities at $6.9 \mathrm{GHz}$ at horizontal (a) and vertical (b) polarizations for about 600 AMSR2 intercepts of the North Atlantic and North Pacific Tropical Cyclones, calculated using equations (6) and (7), as the functions of 10-min maximum sea surface wind speed, taken from the Best Track data.

Since the scatter of the data is quite large both for vertically polarized and for horizontally polarized signal, the equations for the interpolation curves cannot be derived unambiguously. Anyway, analyzing Fig. 3, we would suggest separating the SWS range to several ones and calculating the radiance sensitivity for every range.

The corresponding ocean brightness temperature sensitivities to SWS for several SWS ranges are presented in Table 1.

Table 1. Ocean brightness temperature sensitivities to sea surface wind speed.

\begin{tabular}{|c|c|c|}
\hline $\mathrm{SWS}, \mathrm{m} / \mathrm{s}$ & $\Delta T_{\text {Bocean }^{H}}, \mathrm{~K} /(\mathrm{m} / \mathrm{s})$ & $\Delta T_{\text {Bocean }}{ }^{V}, \mathrm{~K} /(\mathrm{m} / \mathrm{s})$ \\
\hline$<15$ & 0.4 & 0.2 \\
\hline $15-20$ & 0.6 & 0.3 \\
\hline $20-40$ & 0.8 & 0.4 \\
\hline $40-60$ & 1.0 & 0.5 \\
\hline$>60$ & 1.5 & 1.3 \\
\hline
\end{tabular}

Up to $15 \mathrm{~m} / \mathrm{s}$ the sensitivity grows slowly with SWS for both polarizations, with horizontal polarization being almost twice more sensitive to wind speed than vertical polarization. As the wind speed exceed $15 \mathrm{~m} / \mathrm{s}$, the slopes increase steadily with a sharp rise at extremely high winds higher than 55-60 $\mathrm{m} / \mathrm{s}$.

\section{ACKNOWLEGEMENTS}

This research was supported by the Ministry of Education and Science of the Russian Federation Project through the Project RFMEFI61014X0006, agreement \#14.610.21.0006 and by the ESA Support to Science (SMOS+Storm Evolution project).

\section{REFERENCES}

[1] F. J. Wentz, "A model function for ocean microwave brightness temperatures," J Geophys Res, vol. 88, no. C3, pp. 18921908, 1983.

[2] C. Kummerow and R. Ferraro, "Algorithm Theoretical Basis Document: EOS/AMSR-E Level-2 Rainfall," Colo. State Univ. Rep., pp. 1-10, 2007.

[3] C. Surussavadee and D. H. Staelin, "Millimeter-wave precipitation retrievals and observed-versus-simulated radiance distributions: Sensitivity to assumptions," J. Atmospheric Sci., vol. 64, no. 11, pp. 3808-3826, 2007.

[4] S. Y. Matrosov and E. M. Shulgina, "Scattering and attenuation of microwave radiation by precipitation," MGO Trans., vol. 448, pp. 85-94, 1982.

[5] L. M. Mitnik and M. L. Mitnik, "Retrieval of atmospheric and ocean surface parameters from ADEOS-II Advanced Microwave Scanning Radiometer (AMSR) data: Comparison of errors of global and regional algorithms," Radio Sci., vol. 38, no. 4, p. 8065, 2003.

[6] H. J. Liebe and D. H. Layton, "Millimeter-wave properties of the atmosphere: Laboratory studies and propagation modeling," Nat. Tech. Inf. Service Boulder, CO, NTIA Rep. 87-24, 1987.

[7] D. D. Turner, M. P. Cadeddu, U. Lohnert, S. Crewell, and A. M. Vogelmann, "Modifications to the water vapor continuum in the microwave suggested by ground-based $150-\mathrm{GHz}$ observations," IEEE Trans. Geosci. Remote Sens. Lett., vol. 47, no. 10, pp. 3326$3337,2009$.

[8] E. V. Zabolotskikh, L. M. Mitnik, and B. Chapron, "New approach for severe marine weather study using satellite passive microwave sensing," Geophys. Res. Lett., vol. 40, no. 13, pp. 33473350, 2013.

[9] E. Zabolotskikh, L. Mitnik, N. Reul, and B. Chapron, "New Possibilities for Geophysical Parameter Retrievals Opened by GCOM-W1 AMSR2," IEEE J. Sel. Top. Appl. Earth Obs. Remote Sens., vol. PP, no. 99, pp. 1-14, 2015.

[10] "GCOM-W1 Data Providing Service Users Manual." Japan Aerospace Exploration Agency, 2013.

[11] I. P. Mazin and A. K. Khrgian, Clouds and Cloudy Atmosphere. Leningrad: Gidrometeoizdat, 1989. 